\title{
Conserved patterns of integrated developmental plasticity in a group of polyphenic tropical butterflies
}

\author{
Erik van Bergen ${ }^{1,3^{*}}$, Dave Osbaldeston ${ }^{1}$, Ullasa Kodandaramaiah ${ }^{1,2}$, Oskar Brattström ${ }^{1}$, Kwaku Aduse-Poku,4 \\ and Paul M. Brakefield ${ }^{1}$
}

\begin{abstract}
Background: Developmental plasticity is thought to have profound macro-evolutionary effects, for example, by increasing the probability of establishment in new environments and subsequent divergence into independently evolving lineages. In contrast to plasticity optimized for individual traits, phenotypic integration, which enables a concerted response of plastic traits to environmental variability, may affect the rate of local adaptation by constraining independent responses of traits to selection. Using a comparative framework, this study explores the evolution of reaction norms for a variety of life history and morphological traits across five related species of mycalesine butterflies from the Old World tropics.
\end{abstract}

Results: Our data indicate that an integrated response of a suite of key traits is shared amongst these species. Interestingly, the traits that make up the functional suite are all known to be regulated by ecdysteroid signalling in Bicyclus anynana, one of the species included in this study, suggesting the same underlying hormonal regulator may be conserved within this group of polyphenic butterflies. We also detect developmental thresholds for the expression of alternative morphs.

Conclusions: The phenotypic plasticity of a broad suite of morphological and life history traits is integrated and shared among species from three geographically independent lineages of mycalesine butterflies, despite considerable periods of independent evolution and exposure to disparate environments. At the same time, we have detected examples of evolutionary change where independent traits show different patterns of reaction norms. We argue that the expression of more robust phenotypes may occur by shifting developmental thresholds beyond the boundaries of the typical environmental variation.

Keywords: Mycalesine butterflies, Developmental plasticity, Seasonal polyphenism, Reaction norm, Life-history evolution, Bicyclus anynana

\section{Background}

Developmental plasticity, the capacity of a single genotype to generate a range of phenotypes through environmental regulation of development [1], is ubiquitous among plants and animals [2, 3]. Whether developmental plasticity constrains or facilitates adaptive evolution and macro-evolutionary diversification has been the

\footnotetext{
* Correspondence: erikvanbergen.science@gmail.com

'Department of Zoology, University of Cambridge, Downing Street, Cambridge CB2 3EJ, UK

${ }^{3}$ Present Address: Instituto Gulbenkian de Ciência, Rua da Quinta Grande 6, P-2780 Oeiras, Portugal

Full list of author information is available at the end of the article
}

topic of recent debate [4-7]. Adaptive developmental plasticity, wherein an inductive environmental cue triggers the development of a phenotype better suited to a forthcoming environment, allows individuals to cope with environmental heterogeneity across space or time $[8,9]$. By altering the distribution of phenotypes in the same direction as that favoured by directional selection, non-heritable environmentally induced variation has been expected to constrain or slow the rate of adaptive evolution [10]. However, at a macro-evolutionary scale, adaptive plasticity is thought to facilitate the process of local adaptation and diversification by enabling 
populations to successfully invade novel environments and subsequently diverge into independently evolving lineages [11-13]. Empirical support for this theory is provided by a number of examples from plants and animals [14-18]. For instance, the repeated evolution of freshwater ecotypes in the three-spined stickleback (Gasterosteus aculeatus) radiation appears to have been driven by specific patterns of ancestral phenotypic plasticity in the founding oceanic population [19].

Adaptive plastic responses of key traits are often integrated into functional suites to enable a concerted response to external cues and corresponding internal signals [20]. For example, environmentally induced diapause in insects, which involves synchronized responses in behaviour, physiology, morphology, and life history traits, is mediated by common physiological-endocrine processes [21]. The integration and coordination of responses typically results in strong genetic and phenotypic correlations between plastic traits which may affect the rate of adaptation to novel environments by constraining the independent response of plastic traits to selection [22-24]. Comparative investigations of developmental plasticity, within a phylogenetic and ecological framework, have been used to infer the extent to which local adaptation is constrained by correlations between traits and to shed light on the ways by which plasticity may contribute to diversification [13]. Many of these studies have compared the shapes and slopes of reaction norms across environments in closely related species or ecotypes subject to different selection pressures [25-28]. The results of these studies show that synchronized phenotypic responses of plastic traits can become uncoupled during periods of independent evolution to facilitate expansions into novel environments.

The number of in-depth comparative analyses of developmental plasticity in insects is remarkably low, especially considering the significant contribution insect model-systems have made to our understanding of the phenomenon (see Beldade et al. [29]). A group of insects that is particularly interesting in this context is the butterfly subtribe Mycalesina (Nymphalidae: Satyrinae: Satyrini). Mycalesine butterflies have radiated dramatically in Africa (including Madagascar) and Asia yielding over 300 extant species that inhabit a range of tropical and sub-tropical habitats [30]. They began to diversify rapidly in the mid-Miocene when much of the transcontinental forests were replaced by a mosaic of more seasonal open woodland and savannah habitats [31, 32]. Many extant mycalesine species exhibit a striking mode of seasonal polyphenism. The phenomenon is particularly well studied in the African species Bicyclus anynana (Butler, 1879), which has become an important model organism for ecological, evolutionary and developmental biology [33-35]. Seasonal variation in ambient temperature and rainfall are positively correlated across the entire distribution of B. anynana in East Africa. A rise in temperature in open woodland habitats predicts the onset of the rainy season and an increase in host plant density. After this period of increased rainfall the temperature drops significantly and the environment gradually dries out [36]. The predictable relationship between these abiotic factors is thought to have selected for a predictive adaptive response in B. anynana [37], with temperature experienced during final stage of larval development inducing the expression of alternative seasonal morphs.

The most noticeable differences between wet season form (WSF) and dry season form (DSF) adults of B. anynana, and those of many other mycalesines, are the colour patterns on the ventral wing surfaces of the adults which are exposed to predators when the butterflies are at rest [38]. In B. anynana, these differences are strongly associated with the alternative seasonal strategies to avoid predation [39, 40]. In the laboratory, the seasonal forms of B. anynana can be induced by the temperature experienced during the critical period of pre-adult development [41], with low and high temperatures inducing DSF-like and WSF-like phenotypes, respectively. Experiments with this model organism have revealed temperature-induced adaptive plasticity of behavioural [42], physiological [43] and life-history traits [44]. In the case of $B$. anynana, ecdysteroid hormone dynamics during the late-larval and pupal stages regulate development time [45] and mediate the synchronized phenotypic responses of a wide suite of morphological and life history traits, such as the formation of wing pattern elements [4648], starvation resistance and female fecundity [49].

Closely related species of mycalesine butterflies, or even populations belonging to a single species, may be distributed over geographic areas with strikingly different seasonal environments [50, 51]. Seasonal forms have been described for many mycalesine species [38, 52, 53], however, the environmental cues inducing the expression of the alternative developmental pathways are less well understood for mycalesine species other than B. anynana [54]. Species inhabiting rainforests may express significant variation in wing pattern elements without being exposed to substantial seasonal variation in temperature [36]. Furthermore, in many tropical environments around the equator an increase in ambient temperature is associated with periods of limited precipitation [54]. Hence, in these environments the development of a WSF phenotype in response to a rapid rise in temperature would represent a non-adaptive response to the forthcoming environment.

Here, we present a comparative study on temperatureinduced developmental plasticity across five mycalesine species and examine how patterns of developmental plasticity and potential local adaptation vary across closely related species. Multiple thermal environments were included in the laboratory experiments to enable a full analysis of the shape of the reaction norms for a 
wide suite of morphological and life-history traits. The species represent a broad range of ecological conditions in Africa, Madagascar and Asia, and their plastic responses are expected to have evolved in response to different ecological contexts with divergent selective pressures.

In this study, we investigate the potential for trait-independent responses by comparing how plastic traits are correlated within and across species, some of which have evolved in response to differing regimes of habitat seasonality. One of the African mycalesine species, Bicyclus safitza [Westwood, 1850], was collected in an environment where temperature is no longer a reliable predictor of forthcoming environmental conditions. The two Asian species, Mycalesis mineus (Linnaeus, 1758) and Mycalesis perseoides (Moore, 1892), were collected in an environment in which ambient temperature and rainfall are negatively correlated. Among these species, traits which can become uncoupled from the integrated phenotypic response to developmental temperature are predicted to show divergent correlative patterns as a result of differing responses to directional selection. Changes in reaction norm slope or shape are predicted to be greatest for wing pattern elements, and even inverted responses to developmental temperature may have evolved in the species which inhabit environments where a decrease in temperature is associated the onset of the wet season. Selection pressure on life history traits, such as total body size or allocation of mass to abdomen, is not expected to vary considerably across habitats and the reaction norms of these traits are therefore predicted to be more constrained compared to the morphological traits (i.e., wing pattern elements).

Finally, during the study we paid special attention to the patterns of developmental plasticity in Heteropsis iboina (Ward, 1870), a species that inhabits secondary forests and woodlands in Madagascar [55]. While being exposed to alternating warm-wet and cool-dry conditions in the wild, this species is known to have cryptic DSF-like ventral wing patterns throughout the year [55]. This suggests that, regardless of being exposed to a seasonal regime which is very similar to that of $B$. anynana, a more robust phenotype may have evolved in this species.

\section{Methods}

\section{Butterflies and experimental design}

The butterflies used in this study originated from stock populations founded between 2011 and 2013. The laboratory populations of $B$. safitza and $H$. iboina were established from eggs collected in Semuliki National Park in Uganda and Andasibe-Mantadia National Park on Madagascar, respectively. The founders of the laboratory populations of the two Asian species, M. mineus and $M$. perseoides, were collected near the Khao Chong Nature Reserve, Thailand. At least ten gravid females contributed to each stock population. For this study we also re-analysed the life history data and examined the wing material from a reaction norm experiment conducted using $B$. anynana, another mycalesine species from the African mainland (Nkhata Bay, Malawi). Details of this experiment are given in Oostra et al. [44]. Climate data for all locations were obtained from the Climatic Research Unit (CRU) online database which provided mean monthly temperature and precipitation for a period of 109 years [56].

Larvae were reared on young wheat plants (Triticum aestivum) in climate-controlled chambers (Sanyo/Panasonic MLR-350H) at $70 \%$ relative humidity $(\mathrm{RH})$ with a 12:12 L:D cycle. Individuals were randomly divided over four climate-controlled chambers $\left(21{ }^{\circ} \mathrm{C}, 23{ }^{\circ} \mathrm{C}, 25{ }^{\circ} \mathrm{C}\right.$ and $27{ }^{\circ} \mathrm{C}$ ) within 1 day after hatching. Cohorts of 20 larvae per plant were kept inside a sleeve of gauze-like material to ensure non-stressful feeding densities. Sleeves were checked daily and fresh plants provided when needed, to ensure ad libitum feeding conditions. Pre-pupae were collected daily and after pupation the pupae were individually placed in transparent pots until they eclosed. One day after eclosion the adults were frozen to $-20{ }^{\circ} \mathrm{C}$, sexed and stored in small envelopes until further processing. In total, 1243 individuals were included in the temperature reaction norm experiments, with an addition of 358 individuals of $B$. anynana.

\section{Life-history traits}

The larval development time (LDT) and pupal development time (PDT) of each individual were measured as the number of days between hatching of the egg and pupation and the number of days between the final moult and adult eclosion, respectively. Together these measurements give the total development time (DT) of each individual. All pupae were weighed to the nearest $0.1 \mathrm{mg}$ within $24 \mathrm{~h}$ after pupation (Fisherbrand PS-60) and the individual growth rate (GR) was calculated by dividing the natural logarithm of the pupal weight (PW) by the LDT (see Gotthard et al. [57]). All adults were carefully dissected, initially by removing the wings and legs. Subsequently, the abdomen and thorax were separated, dried to constant mass $\left(60{ }^{\circ} \mathrm{C}\right.$ for $24 \mathrm{~h})$ and weighed individually, yielding total dry mass $(\mathrm{DM})$ as well as the relative allocation of adult body mass to the abdomen (RA). Total fat (triglyceride and free fatty acids) was extracted by incubating the dried body parts at room temperature in 2:1 (v/v) dichloromethane:methanol for $96 \mathrm{~h}$, followed by drying and re-weighing of the body parts. Absolute fat content was calculated by subtracting the fat-free dry weight from the initial dry mass after which the relative fat content (FC) was computed by dividing absolute fat content by the initial dry mass [58].

\section{Wing pattern elements}

The ventral and dorsal surface of one hind- and one forewing of each individual were imaged using a Leica 
DFC495 digital camera coupled to a Leica M125 stereomicroscope and the photographs analysed with the image processing package Fiji [59]. Phenotypic traits on the wing surfaces can be measured with high repeatability with this image analysis system (overall $\mathrm{R}^{2}=0.978 \pm$ 0.023; see Additional file 1). On the ventral hindwing, the area of the yellow outer ring, the black inner-disc, and white focus of the eyespot in cell $\mathrm{Cul}$ were measured. In addition, the relative distance of the proximal edge of the median band along the second wing vein was taken as a measure of the width of the band, which is difficult to measure directly because of its indistinct distal edge (adjusted from Wijngaarden \& Brakefield [60]). The measurements on the ventral forewing included the yellow, black and white areas of the eyespot in cell M1 as well as area of the black inner-disc of the larger eyespot in cell $\mathrm{Cu} 1$. On the dorsal forewing we measured the area of the yellow outer ring, the black disc, and white focus of the large eyespot in cell $\mathrm{Cu} 1$ and, if present, the smaller eyespot in cell M1. For all wings an area enclosed by three clear landmarks was used as a proxy of wing size. See Fig. 1 for a graphic overview of all measured wing pattern elements. References to wing veins and cells follow the Comstock-Needham system [61].

\section{Statistical analyses}

All statistical analyses were performed with the R Statistical Package v 3.1.2 [62]. All development times were log-transformed to improve normality. The abdomen ratio and relative fat content were arcsine transformed and wing pattern elements were corrected for wing size. Two-way ANOVAs were used to analyse the effect of developmental temperature and sex on each phenotypic trait of interest for each species. Full models were fitted

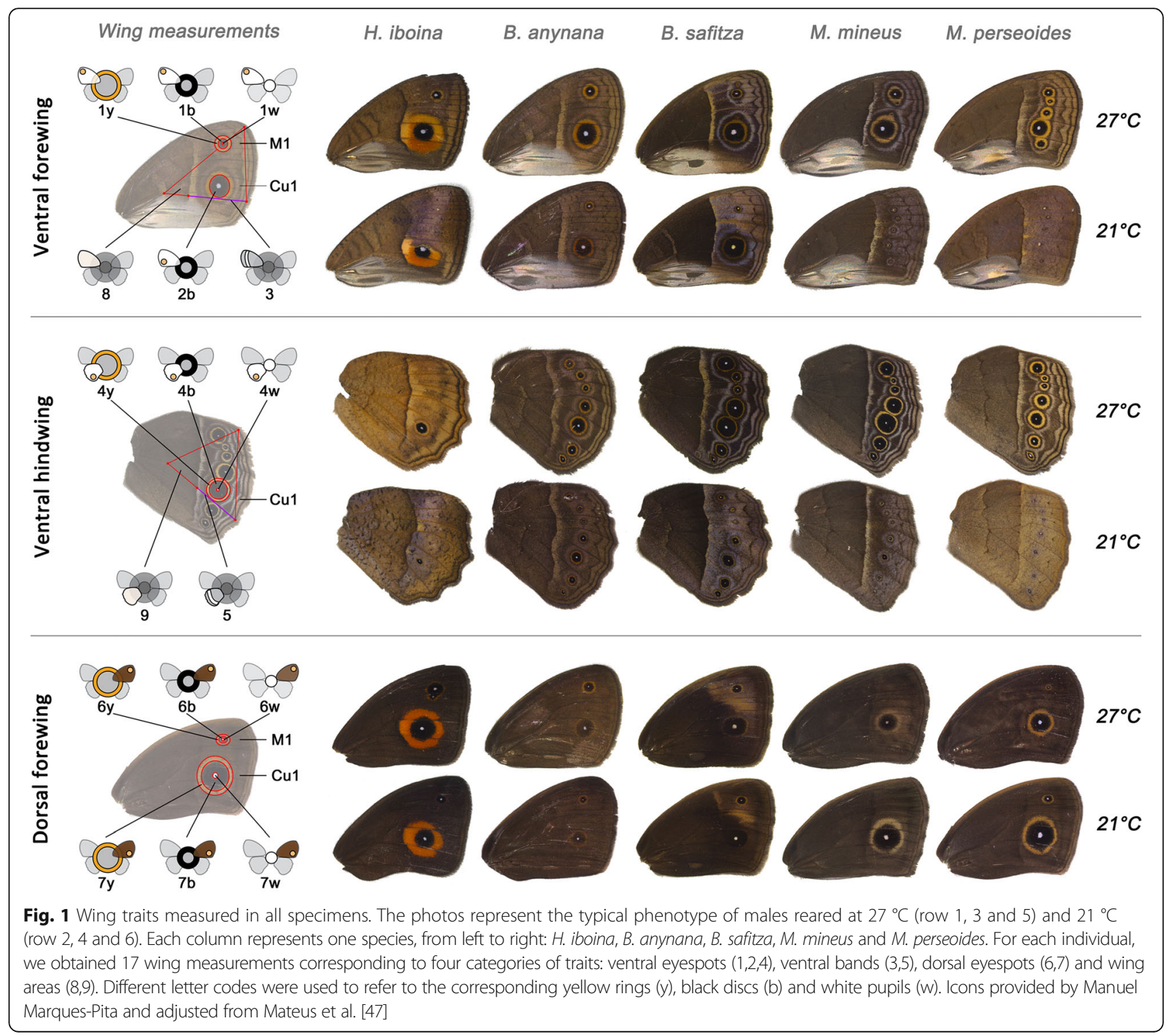


initially including temperature, sex, and their interaction as fixed factors, before removal of non-significant terms successively. Correlation matrices were used to demonstrate the integration of plastic responses, and to elucidate which traits are or have become uncoupled from the synchronized response to developmental temperature.

Nine wing-pattern measurements of the ventral wing surface (traits 1-5; see Fig. 1) were reduced using a

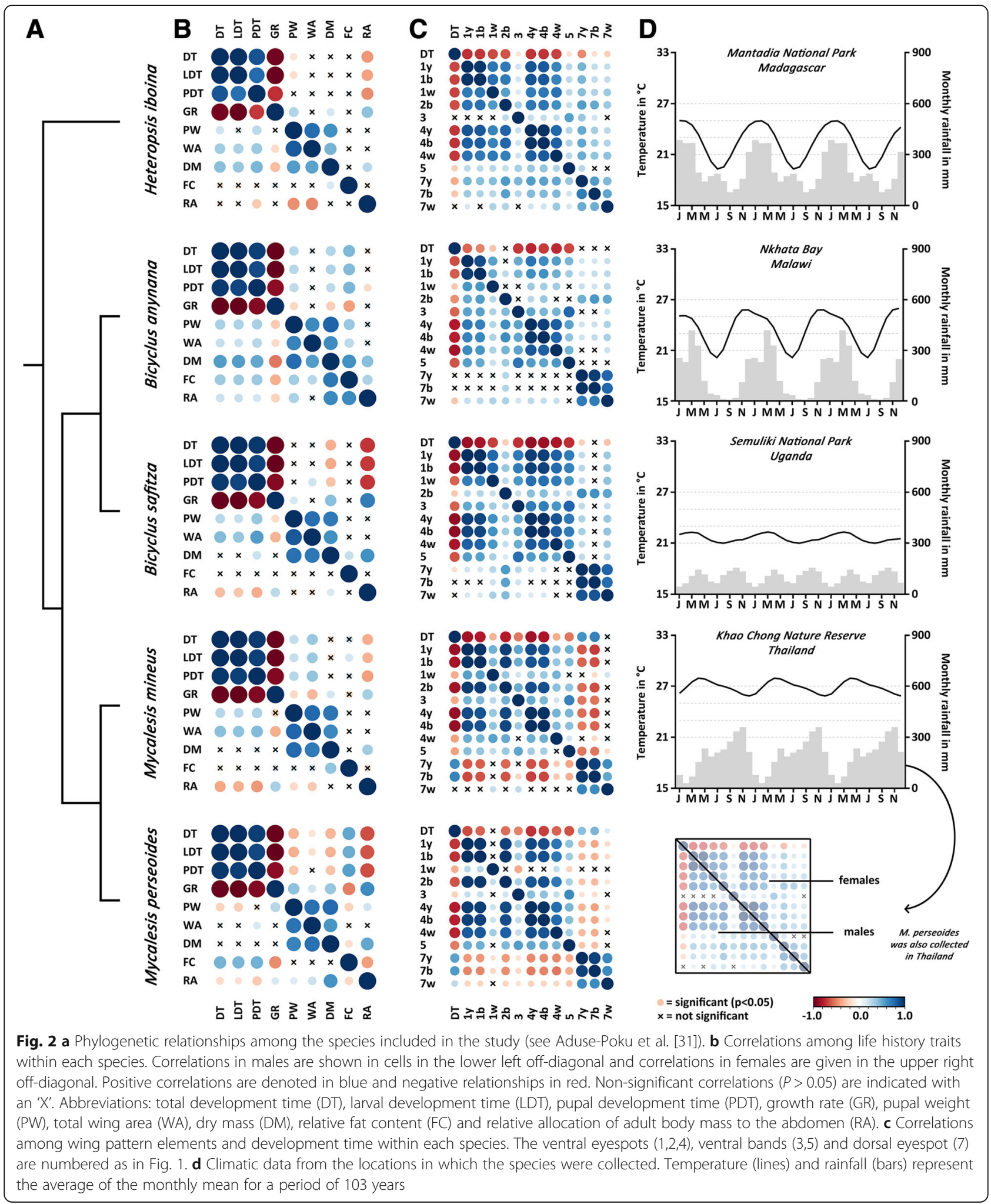


principal component analysis, pooling data per species across the sexes. For each species, the first principal component (PC1) explained approximately $60 \%$ of the total variation and was strongly associated with the effect of the developmental temperature (Additional file 2). PC2 explained approximately $15 \%$ of the variation in each species and was correlated with the sex rather than seasonality. Therefore, only PC1 was used to analyse the general phenotypic response of the ventral wing surface (see supplementary material). Post hoc comparisons between specific levels of the factors were performed using Tukey's honest significant differences (HSD) tests.

The relationship between developmental time and PC1 was explored by performing piecewise linear regressions, with development time as dependent variable and sex as covariate, using the 'segmented' package in $R$ [63]. The existence of one or several inflection points and significant differences in slopes was tested using Davies' tests $[64,65]$, after which the positions of the inflection points (i.e., the developmental thresholds) and 95\% confidence intervals were estimated.

\section{Results}

In all species studied here, most life history traits and wing pattern elements showed a significant response to developmental temperature. However, the shape of the reaction norms as well as the direction of the response varied significantly across species for several traits. Moreover, traits which showed significant responses to the temperature treatments were also highly correlated with developmental time in all species (Fig. 2). All minimum adequate models and reaction norm representations are presented in Additional files 3 and 4 . Additional file 5 includes a comprehensive summary of all results, while we present the most salient results here.

\section{Developmental times and body size}

In all species and both sexes, total egg to adult development time (DT) was strongly affected by developmental temperature $\left(21>23>25>27{ }^{\circ} \mathrm{C}\right)$. Male larvae developed significantly faster than female larvae, while during the pupal stage, females of all species developed faster than males. The effect of the latter was small and protandry was present in all species at all developmental temperatures. Total wing area (WA), pupal weight (PW) and adult dry mass (DM) were significantly affected by developmental temperature in all species, with the exception of DM in B. safitza. The shapes of the reaction norms varied significantly among species and across these body size traits but overall we observed a consistent trend for larger individuals at lower temperatures $\left(21>27{ }^{\circ} \mathrm{C}\right)$ for most species. Females were significantly larger than males across all temperatures and all species had significantly higher growth rates (GR) when reared at higher temperatures (see Additional file 3a-g).

\section{Fat content}

In $B$. anynana and $M$. perseoides, adult relative fat content (FC) decreased significantly with increasing developmental temperature in both sexes. In contrast, FC was

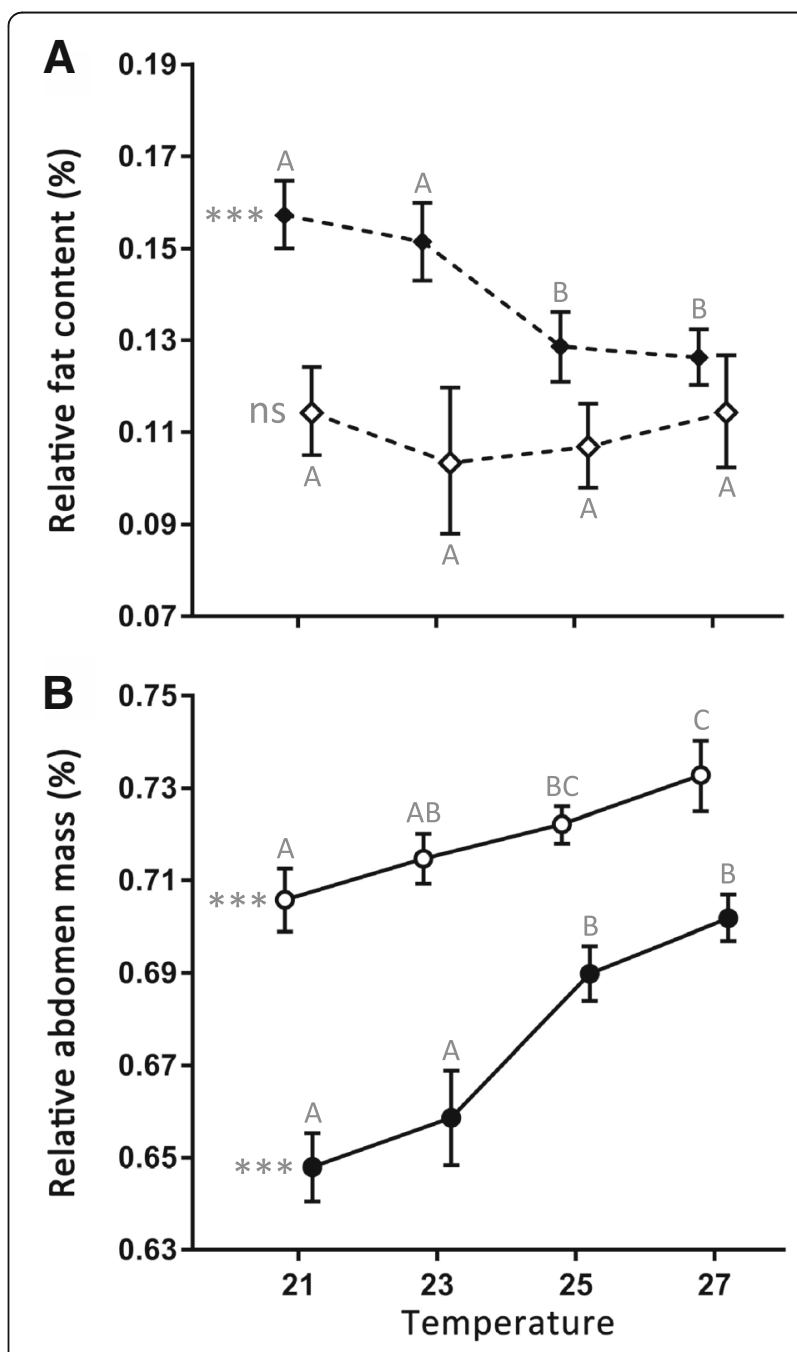

Fig. 3 Effects of developmental temperature on relative fat content (a) and abdomen mass (b). The mean value is plotted as a function of temperature and these representations, called reaction norms, are the standard way of displaying plasticity. Panel a shows the relative fat content in males from M. perseoides (filled symbols) and M. mineus, (open symbols). Panel $\mathbf{b}$ represents the relative investment in abdomen mass by females from $H$. iboina (open symbols) and $B$. safitza (filled symbols). Statistical significance for effects of temperature on the life history trait is indicated to the left of each reaction norm: ns (non-significant) $=P>0.05$ and ${ }^{* *}=p<0.001$. Error bars represent $95 \%$ confidence intervals and significant differences across the temperature treatments (Tukey's HSD, $p<0.05$ ) are indicated by different letters, coding for each species separately. All minimum adequate models and reaction norm representations are presented in the supplementary materials 
not affected by temperature, nor correlated with developmental time, in either sex of B. safitza, M. mineus and H. iboina (Fig. 3a; Additional file 3h). In B. anynana, male FC did not change along the temperature gradient, with the exception of $27{ }^{\circ} \mathrm{C}$ where it was significantly lower compared to the other temperature treatments. Females of $B$. anynana developed the highest FC when reared at $21{ }^{\circ} \mathrm{C}$ (see also Oostra et al. [44]). In $M$. perseoides, the response to temperature was discontinuous with a developmental threshold between $23{ }^{\circ} \mathrm{C}$ and $25{ }^{\circ} \mathrm{C}$ for both females and males (Fig. 3a). In all species, FC of females was significantly lower than in males.

\section{Abdomen ratio}

Individuals of all species allocated relatively more mass to the abdomen (RA) when reared at higher temperatures (Additional file 3i). In general, the effect of the temperature treatment on RA was particularly pronounced in females but, in most species, males responded in a similar way. Relationships between developmental temperature and phenotypic variation in RA ranged from linear responses, for example in females of $H$. iboina (Fig. 3b), to more discontinuous responses to temperature, as observed in females of B. safitza. The latter species allocated relatively more mass to the abdomen when reared at either of the two higher temperature treatments (Fig. 3b).

\section{Dorsal wing surface}

The analyses of the wing pattern elements on the dorsal surface revealed significant species-specific responses to developmental temperature. In both Bicyclus species, $B$. anynana and $B$. safitza, the large eyespot in cell $\mathrm{Cu} 1$ is relatively insensitive to developmental temperature while in the other three species the same eyespot was strongly affected by the same treatment (Fig. 4). In $H$. iboina, dorsal eyespot size increased almost linearly with increasing temperature, yielding large eyespots when reared at high temperatures. In contrast, in both Mycalesis species, M. mineus and M. perseoides, this pattern was reversed, showing a significant decrease in dorsal eyespot size with increasing temperatures; hence these species had small dorsal eyespots when

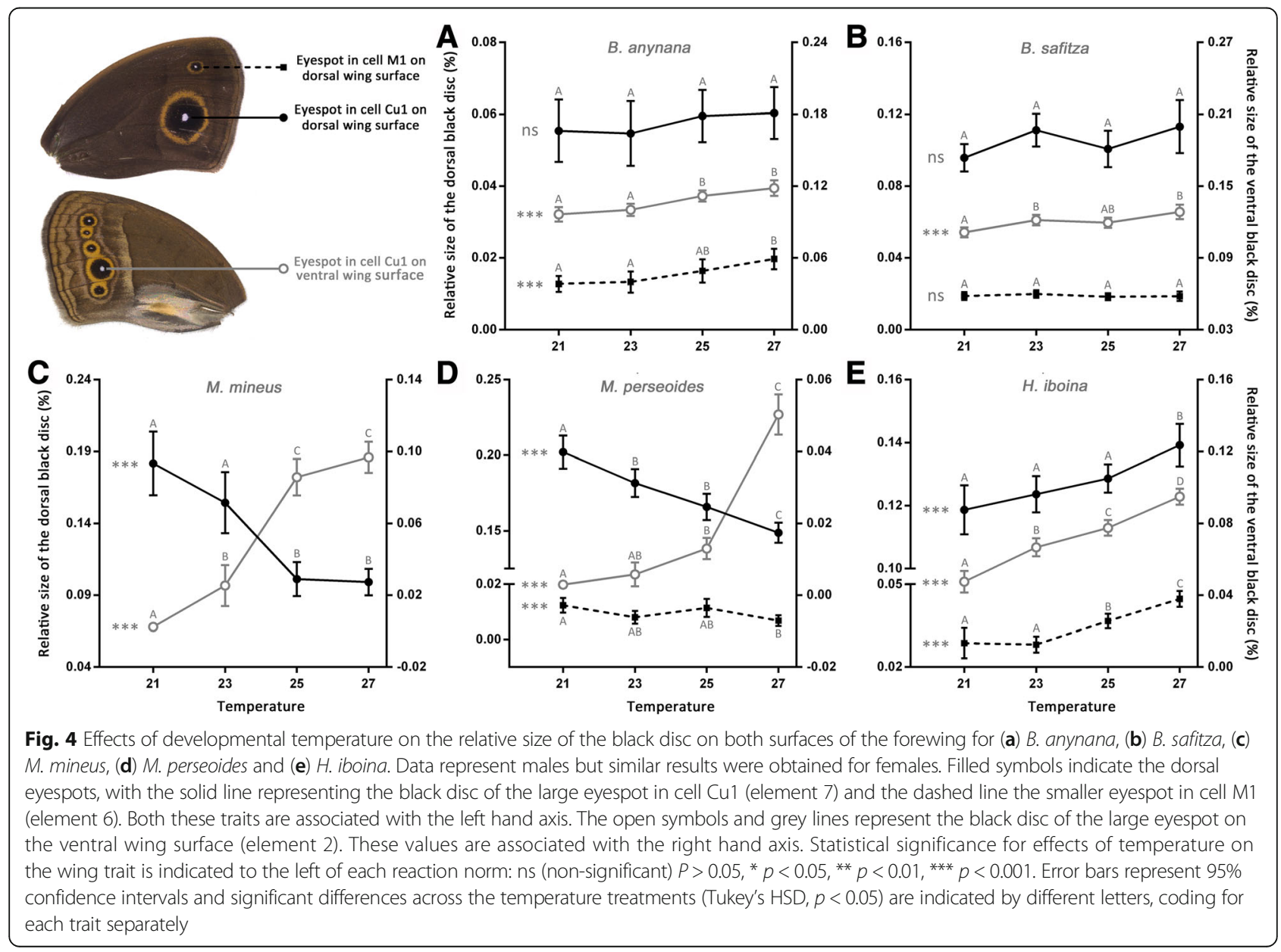


reared at high temperatures (Fig. $4 \mathrm{~d}$ and e). Similar responses were obtained for the small eyespot on the same wing surface with the exception that in $B$. anynana this eyespot was significantly affected by developmental temperature and became larger with increasing temperature (Fig. 4a).

\section{Ventral wing surface}

Most wing pattern elements on the ventral surface were strongly affected by the developmental temperature in all species, with higher temperatures yielding more conspicuous patterns (Fig. 5a-e). In $B$. anynana, the ventral wing patterns (PC1) responded almost linearly to developmental temperature, resulting in intermediate phenotypes at intermediate temperatures. In contrast, the relationship between the temperature and phenotypic gradient was non-linear in the other four species. The ventral wing patterns of $B$. safitza and M. mineus increased dramatically between $23{ }^{\circ} \mathrm{C}$ and $25{ }^{\circ} \mathrm{C}$. As a consequence, in these two species, individuals reared at the extremes of the temperature gradient showed a very close phenotypic resemblance. In $M$. perseoides and $H$. iboina, the ventral wing patterns responded in an almost exponential manner to the temperature treatment, with a sharp increase between the two highest experimental temperatures. In addition, ventral wing patterns elements which demonstrated a clear response to variation in temperature were also significantly correlated with developmental time in all species (Fig. 2), such that faster developing individuals yield more conspicuous patterns.

\section{Developmental thresholds}

The relationship between the ventral wing patterns (PC1) and developmental time mirrored the shape of the reaction norms, and we used this relationship to determine the presence of developmental thresholds for $\mathrm{PC} 1$ in these species (Fig. $5 \mathrm{f}-\mathrm{j}$ ). The variation in the ventral wing pattern elements of B. anynana correlates linearly with variation in developmental time, while in all other species significant inflection points were detected. In $H$. iboina, the relationship between PC1 and development time has a significant change in slope around a single inflection point (Davies' test for a change in the slope, $p<0.001)$ at 48.2 days $(95 \%$ CI: 45.1-51.5). In M. perseoides we also detected a single inflection point $(p<0.001)$ at 39.8 days (95\% CI: $38.1-$ 41.6). The relationship between PC1 and development time followed an S-shaped trajectory in B. safitza and had significant changes in the slope around two inflection points (both $p<0.05$ ). Only a short developmental period between the first (36.0; CI: 34.2-37.9) and the second inflection point (45.7; CI: 43.7-47.9) leads to the induction of intermediate phenotypes. A similar pattern was found for M. mineus, with an initial significant developmental threshold (35.3; CI: 33.1-37.7). However, in this species, the secondary inflection point, predicted at 44.1, was not significant $(P=0.28)$.

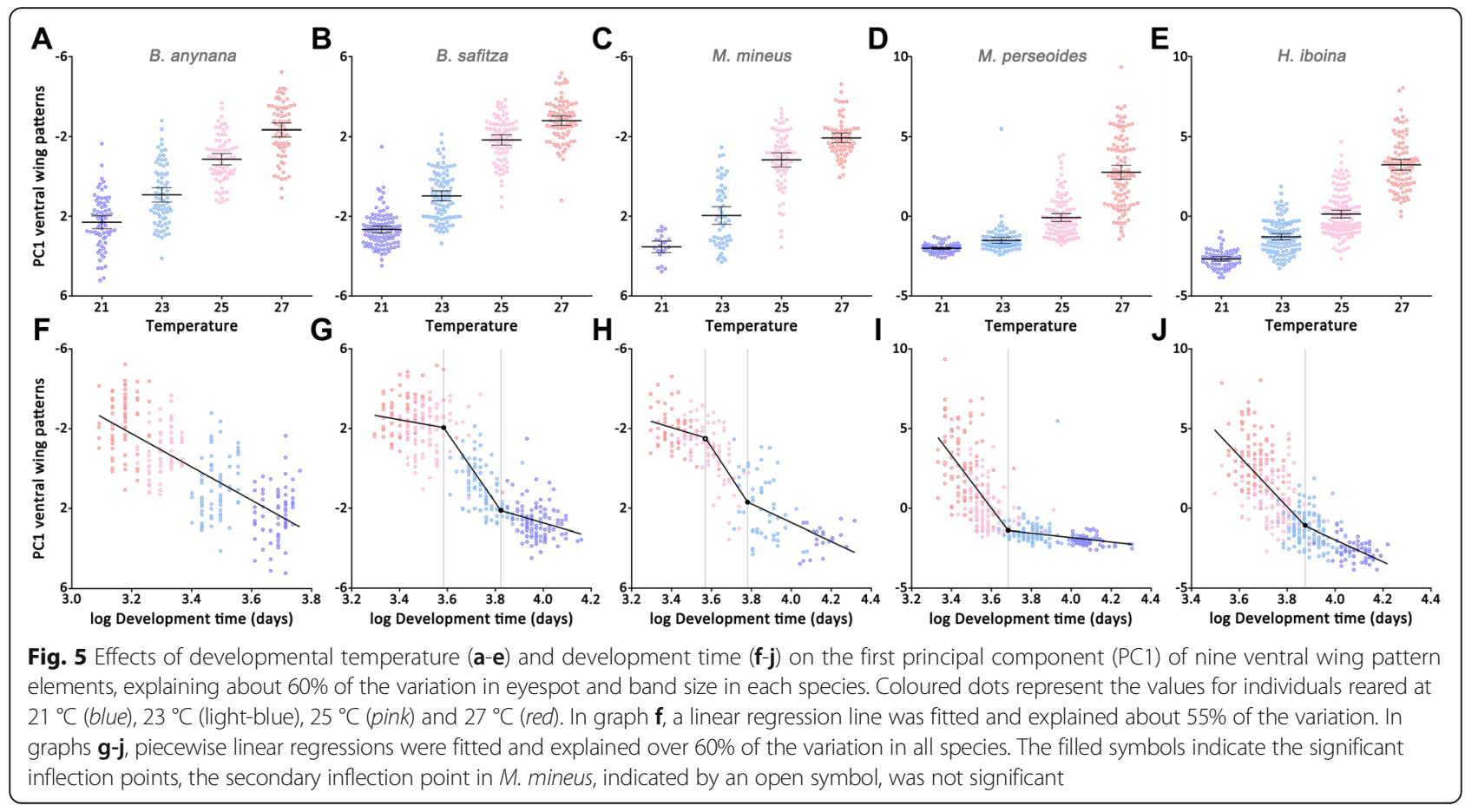




\section{Discussion}

\section{Integrated responses to environmental stress are} conserved

All mycalesine species included in this study demonstrated temperature-induced developmental plasticity. In general, individuals reared at lower temperatures not only develop slower but are also larger and have lower growth rates, which seems to be the norm for ectotherms [66]. As predicted, correlative patterns among these life history traits, as well as reaction norms shapes, were highly conserved across all species. Moreover, despite the fact that the species represent considerable periods of independent evolution and occurrence in disparate environments, we also demonstrate that all species invest less in reproduction (i.e., reduced allocation of body mass to the abdomen) and possess less conspicuous ventral wing patterns when reared at lower temperatures. Interestingly, the responses to developmental temperature in relative abdomen mass and ventral wing patterning are known to be regulated by ecdysteroid signalling in $B$. anynana. Ecdysteroid injections during the early pupal stage accelerate development, increase body mass allocation to abdomen in females [49] and induce the expression of more conspicuous ventral wing patterns $[47,48]$. In B. anynana, several other life history traits co-vary with the traits examined here in their response to developmental temperature. For example, a higher resistance to starvation [43] and increased longevity in adults [67] are associated with exposure to lower developmental temperatures and respond in similar directions to manipulations of internal levels of ecdysone [49]. The evolution of this particular functional suite, in which the plastic responses of key traits are integrated to express a coordinated environmental response, is anticipated to be an adaptation to variability in environmental stress in B. anynana. The direction of the response to the temperature gradient was very similar across all species for the traits that make up the functional suite which suggests that the sharing of the same underlying hormonal regulator may be conserved within the mycalesine subtribe (see Additional file 5 for a summary table of the results).

\section{Correlated responses of independent traits}

The presence of strong phenotypic correlations between traits does not necessarily imply that plastic responses are integrated and mediated by the same internal signals. The lack of response to temperature for relative fat content (FC) in B. safitza, M. mineus and H. iboina observed in this study could be interpreted as an example of a trait which has become uncoupled from the synchronized response to environmental variation in these species. Thus, while the responses to temperature are very similar for all traits of the functional suite in these five species, FC could respond independently to the selective forces experienced in novel environments. Such uncoupling may be because
FC in these species is not regulated by pupal ecdysteroid dynamics, although ecdysteroid injections have been shown to induce higher abdominal fat content in B. anynana females [49]. Alternatively, it is also possible that FC does respond to temperature in B. safitza, M. mineus and $H$. iboina, but the threshold temperature at which FC is altered in these species may lie outside the range of temperatures used in this study.

In this context, one particularly intriguing result of this study is the variation in the plastic responses of the eyespots on the dorsal wing surface. In contrast to the ventral wing surface, where all pattern elements were highly correlated and responded in the same direction in all species, there were striking differences across species in the responses of the patterns on the dorsal wing surface to developmental temperature. In $H$. iboina, the size of the dorsal eyespot (wing pattern element 7; see Figs. 1 and 3) was positively correlated with the ventral wing patterns and increased with increasing temperature. In contrast, in both Mycalesis species, the dorsal eyespot size responded in the opposite direction to the same environmental gradient and this trait was negatively correlated with the patterns on the ventral wing surface. Furthermore, in these species the ventral and dorsal eyespots of same wing not only responded in opposite directions but also with very different dynamics (i.e., different reaction norm shapes; Fig. 4). Finally, in both Bicyclus species the same eyespot was largely insensitive to variation in developmental temperature, which confirms the results of previous studies on dorsal wing patterning in B. anynana [42, 68]. Interestingly, in this species, pattern elements on the dorsal wing surface do not respond to ecdysone titre manipulations [47]. This validates the idea that colour pattern formation on both wing surfaces is independent $[69,70]$ and suggests that the two developing tissues respond to different internal signals. In addition, these results demonstrate that antagonistic responses to the same inductive environmental cue can evolve independently among a group of closely related species.

\section{Eyespots and antipredator strategies}

In $B$. anynana, wet season form adults (WSF) show conspicuous eyespots on the ventral wing surfaces, positioned close to the margin of the wing. These eyespots function to deflect the attacks of predators to regions of the body that are non-vital and, thus, increase adult survival and fitness $[39,40]$. In contrast, dry season form adults (DSF) of $B$. anynana have virtually no ventral eyespots, relying on being cryptic when at rest against a background of leaf litter to evade predators [71]. During this study we paid special attention to the patterns of developmental plasticity in $H$. iboina. Unlike the other four species, this species from Madagascar has a cryptic DSFlike appearance throughout the year, and we hypothesised 
that, regardless of being exposed to substantial seasonal variation, a more robust and less plastic phenotype had evolved in this species. In contrast, we found that most life history traits and measured wing pattern elements showed a significant response to developmental temperature in $H$. iboina, demonstrating that the cryptic phenotype of this species is not achieved by a (complete) loss of plasticity for ventral wing patterns. Instead, crypsis seems to be maintained due to the effective absence of expression of several marginal eyespots on the ventral hindwing - possibly via a shift of the reaction norm along the developmental environmental axis - where the other four species demonstrate a pattern of serially repeated eyespots on the ventral hindwing (see Fig. 1). This may indicate that ventral deflective eyespots are less advantageous in this species. Interestingly, a ritualised display or 'startling' behaviour involving the sudden exposure of highly conspicuous eyespots on the dorsal surface has been observed frequently in $H$. iboina in the field (personal observations). Such displays have been shown to be effective in startling potential vertebrate predators to increase the probability of escape in numerous other species of Lepidoptera $[72,73]$. The startle behaviour of $H$. iboina may be an alternative adaptation to avoid predation in the Malagasy forests.

In this context, for the two species from Asia, Mycalesis mineus and Mycalesis perseoides, which inhabit an environment in which ambient temperature and rainfall are negatively correlated, the integrated response of ventral wing patterns to developmental temperature could be maladaptive. Individuals with cryptic ventral wing patterns may only start to emerge in the early wet season when dead, brown leaf litter is expected to be less abundant. This suggests that the power of selection, favouring conspicuous ventral eyespots for deflection during the wet season, may be constrained by the integration of plastic responses in these species. Alternatively, these species may use environmental cues other than temperature to match their seasonal forms with the seasonality of the climate [54]. Remarkably, in both Mycalesis species the eyespots on the dorsal wing surface respond in the opposite direction to developmental temperature and individuals with large dorsal eyespots are expected to emerge during the wet season based on our experimental data. Alternative anti-predator behaviour could have evolved in these species in response to a lower evolvability of the ventral wing patterns. Our data indicate that it is now timely to assess how patterns of plasticity are related to the evolution of species-specific antipredator strategies.

\section{Developmental time and thresholds}

Our results clearly indicate that rearing temperature alone can induce plastic responses in mycalesine butterflies, however little is known about the effect of the environmental complexity to which populations are exposed in the wild. In this study all the traits that showed a clear response to temperature were also highly correlated with developmental time. Based on observations from laboratory work with $B$. anynana it can be hypothesized that any environmental factor which influences the duration of pre-adult development could act as a morph-determining, predictive cue [71]. For example, food limitation during larval development [74] and a reduced nutritional quality of the diet $[75,76]$ are strongly associated with longer development times and the induction of more DSF-like phenotypes. In addition, populations which are exposed to daily fluctuations in temperature or thermoperiods during development have larger eyespots and complete pre-adult development faster [77].

By using development time as a proxy for environmental variation during pre-adult growth we detected clear developmental thresholds for the expression of ventral wing pattern elements in all the non-model-species. Whenever developmental time exceeded these thresholds, transition into the alternative seasonal morph occurred. The pattern of B. safitza and M. mineus followed a trajectory which is typical of polyphenism. The induction of intermediate phenotypes, which may have lower fitness depending on the natural environment, only occurred during a restricted range of developmental times. In $H$. iboina and $M$. perseoides, we detected single inflection points in the developmental reaction norms. However, a second inflection point and levelling off of the phenotypic response may lie outside the temperature range used in this study. Alternatively, this phenomenon could be related to selection regimes and patterns of local adaptation in the wild. For example, by shifting the developmental threshold outside the boundaries of the typical temperature gradient, species will yield a more robust phenotype in the natural environment without losing the ability to express phenotypic plasticity when exposed to novel environments (see also Ghalambor et al. [13]). In B. anynana, the variation in the ventral wing pattern elements correlated linearly with variation in developmental time and intermediate phenotypes are induced at intermediate temperatures. However, extensive longitudinal surveys in a seasonal environment in Malawi suggest that such intermediate temperatures may not persist for sufficient time during key periods of larval development to induce (many) intermediate adult phenotypes in the wild [78].

\section{Conclusions}

This study aimed to explore further the role of plasticity in driving patterns of evolutionary diversification; does it facilitate some directions of phenotypic evolution whilst also tending to limit change in other directions? Our 
results provide some support for the latter notion. Thus, we demonstrate that the integrated phenotypic plasticity of a broad suite of morphological and life history traits is shared among species from three geographically independent lineages of mycalesine butterflies, but at the same time, there are examples of evolutionary change where independent traits show different, 'uncoupled' patterns of reaction norm evolution. More extensive studies, made in combination with assays of phenotypic plasticity in the wild and analysed in a comparative phylogenetic framework, will be needed to examine more rigorously how phenotypic plasticity evolves among related species, and how conserved patterns of plasticity, based as here in a shared physiology, may influence subsequent patterns of reaction norm evolution.

\section{Additional files} Additional file 1: Repeatability estimates for wing pattern elements.
(PDF $17 \mathrm{~kb}$ )

Additional file 2: Results of the principal component analyses (PCA) for wing pattern elements. (PDF $22 \mathrm{~kb}$ )

Additional file 3: Reaction norm graphs and minimum adequate models for all life history traits. (PDF $702 \mathrm{~kb}$ )

Additional file 4: Reaction norm graphs and minimum adequate models for all wing pattern elements. (PDF $1359 \mathrm{~kb}$ )

Additional file 5: Summary table of the plastic responses to developmental temperature in mycalesine butterflies. (PDF $29 \mathrm{~kb}$ )

Additional file 6: Raw dataset used in this study. (XLSX $581 \mathrm{~kb}$ )

\section{Abbreviations}

DM: Dry mass; DSF: Dry season form; DT: Total development time; FC: Relative fat content; GR: Growth rate; LDT: Larval development time; PDT: Pupal development time; PW: Pupal weight; RA: Relative allocation of adult body mass to the abdomen; WA: Total wing area; WSF: Wet season form

\section{Acknowledgements}

We are grateful to Elvira Lafuente and three anonymous reviewers for suggestions which greatly improved early versions of our manuscript, to Andrew Balmer, Lea van der Graaf and Jamie Gundry for practical assistance, and Vicencio Oostra and Maaike de Jong for providing the samples and data from B. anynana.

\section{Funding}

This work was supported by the European Research Council grant EMARES (250325) and the John Templeton Foundation grant \#60501. During the final stages of the project EvB was supported by funding from the Portuguese Foundation for Science and Technology (FCT; ref: PTDC/BIA-EVF/0017/2014), and UK was funded through the INSPIRE Faculty Award by the Department of Science and Technology, India.

\section{Availability of data and materials}

Raw data are available in Additional file 6.

\section{Authors' contributions}

EvB, UK, OB and PMB conceived and designed the experiments; EvB, DMO, UK, KAP and OB established the stock populations and performed the experiments. EvB analysed the data and wrote the manuscript. All authors read and approved the final version of the manuscript for publication.

\section{Competing interests}

The authors declare that they have no competing interests.
Consent for publication

Not applicable.

Ethics approval and consent to participate

Not applicable.

\section{Author details}

${ }^{1}$ Department of Zoology, University of Cambridge, Downing Street, Cambridge CB2 3EJ, UK. ${ }^{2}$ School of Biology, Indian Institute of Science Education and Research Thiruvananthapuram, CET campus, Trivandrum 695016, India. ${ }^{3}$ Present Address: Instituto Gulbenkian de Ciência, Rua da Quinta Grande 6, P-2780 Oeiras, Portugal. ${ }^{4}$ Present Address: Department of Biology, City College of New York, City University of New York, Convent Avenue at 138th Street, New York, NY 10031, USA.

Received: 25 October 2016 Accepted: 8 February 2017

Published online: 27 February 2017

\section{References}

1. Bradshaw AD. Evolutionary Significance of Phenotypic Plasticity in Plants. In: Advances in Genetics. Caspari EW, Thoday JM, eds. Vol. 13. London: Academic Press; 1965. pp. 115-55.

2. Sultan SE. Phenotypic plasticity for plant development, function and life history. Trends Plant Sci. 2000;5(12):537-42.

3. Nijhout HF. Development and evolution of adaptive polyphenisms. Evol Dev. 2003:5(1):9-18.

4. Laland KN, Uller T, Fellman MW, Sterelny K, Muller GB, Moczek A, Jablonka E, Odling-Smee J. The extended evolutionary synthesis: its structure, assumptions and predictions. Proc R Soc B-Biol Sci. 2015;282(1813):20151019.

5. Pfennig DW, Wund MA, Snell-Rood EC, Cruickshank T, Schlichting CD, Moczek AP. Phenotypic plasticity's impacts on diversification and speciation. Trends Ecol Evol. 2010;25(8):459-67.

6. West-Eberhard MJ. Developmental Plasticity and Evolution. 198 Madison Avenue. New York: New York 10016: Published by Oxford University Press, Inc; 2003.

7. Schneider RF, Meyer A. How plasticity, genetic assimilation and cryptic genetic variation may contribute to adaptive radiations. Mol Ecol. 2017; 26(1):330-50.

8. Scheiner SM. Genetics and Evolution of Phenotypic Plasticity. Annu Rev Ecol Syst. 1993;24:35-68

9. Brakefield PM, Zwaan BJ. Seasonal polyphenisms and environmentally induced plasticity in the Lepidoptera: The coordinated evolution of many traits on multiple levels. In: Flatt T, Heyland A, editors. Mechanisms of Life History Evolution: The Genetics and Physiology of Life History Traits and Trade-Offs. Oxford: Oxford University Press; 2011. p. 478.

10. Falconer DS. Introduction to Quantitative Genetics. 2nd ed. New York: Longmans; 1981.

11. Baldwin JM. A New Factor in Evolution. Am Nat. 1896:30(354):441-51.

12. Yeh PJ, Price TD. Adaptive phenotypic plasticity and the successful colonization of a novel environment. Am Nat. 2004;164(4):531-42.

13. Ghalambor CK, McKay JK, Carroll SP, Reznick DN. Adaptive versus nonadaptive phenotypic plasticity and the potential for contemporary adaptation in new environments. Funct Ecol. 2007;21(3):394-407.

14. Griffith TM, Sultan SE. Shade tolerance plasticity in response to neutral vs green shade cues in Polygonum species of contrasting ecological breadth. New Phytol. 2005;166(1):141-7.

15. Gomez-Mestre I, Buchholz DR. Developmental plasticity mirrors differences among taxa in spadefoot toads linking plasticity and diversity. Proc Natl Acad Sci U S A. 2006:103(50):19021-6.

16. Wund MA, Baker JA, Clancy B, Golub JL, Fosterk SA. A test of the "Flexible stem" model of evolution: Ancestral plasticity, genetic accommodation, and morphological divergence in the threespine stickleback radiation. Am Nat. 2008;172(4):449-62.

17. Scoville AG, Pfrender ME. Phenotypic plasticity facilitates recurrent rapid adaptation to introduced predators. Proc Natl Acad Sci U S A. 2010;107(9):4260-3.

18. Susoy V, Ragsdale EJ, Kanzaki N, Sommer RJ. Rapid diversification associated with a macroevolutionary pulse of developmental plasticity. Elife. 2015;4: e05463.

19. Wund MA, Valena S, Wood S, Baker JA. Ancestral plasticity and allometry in threespine stickleback reveal phenotypes associated with derived, freshwater ecotypes. Biol J Linn Soc. 2012;105(3):573-83. 
20. Whitman DW, Agrawal AA. What is phenotypic plasticity and why is it important? In: Phenotypic plasticity of insects. Whitman DW, Ananthakrishnan TN eds. Enfield: Science Publishers; 2009. pp. 1-63.

21. Denlinger DL. Regulation of diapause. Annu Rev Entomol. 2002;47:93-122.

22. Agrawal AF, Stinchcombe JR. How much do genetic covariances alter the rate of adaptation? Proc R Soc B-Biol Sci. 2009;276(1659):1183-91.

23. Smith RA, Rausher MD. Selection for Character Displacement Is Constrained by the Genetic Architecture of Floral Traits in the Ivyleaf Morning Glory. Evolution. 2008;62(11):2829-41.

24. Lande R. Quantitative Genetic-Analysis of Multivariate Evolution, Applied to Brain-Body Size Allometry. Evolution. 1979;33(1):402-16.

25. Moczek AP. Integrating micro- and macroevolution of development through the study of horned beetles. Heredity. 2006;97(3):168-78.

26. Morey S, Reznick D. A comparative analysis of plasticity In larval development in three species of spadefoot toads. Ecology. 2000;81(6):1736-49.

27. Handelsman CA, Ruell EW, Torres-Dowdall J, Ghalambor CK. Phenotypic Plasticity Changes Correlations of Traits Following Experimental Introductions of Trinidadian Guppies (Poecilia reticulata). Integr Comp Biol. 2014;54(5):794-804.

28. Parsons KJ, Robinson BW. Replicated evolution of integrated plastic responses during early adaptive divergence. Evolution. 2006;60(4):801-13.

29. Beldade P, Mateus ARA, Keller RA. Evolution and molecular mechanisms of adaptive developmental plasticity. Mol Ecol. 2011;20(7):1347-63.

30. Kodandaramaiah U, Lees DC, Muller CJ, Torres E, Karanth KP, Wahlberg N. Phylogenetics and biogeography of a spectacular Old World radiation of butterflies: the subtribe Mycalesina (Lepidoptera: Nymphalidae: Satyrini). BMC Evol Biol. 2010;10:172

31. Aduse-Poku K, Brattström O, Kodandaramaiah U, Lees DC, Brakefield PM, Wahlberg N. Systematics and historical biogeography of the Old World butterfly subtribe Mycalesina (Lepidoptera: Nymphalidae: Satyrinae). BMC Evol Biol. 2015;15:167.

32. Nokelainen O, Ripley BS, van Bergen E, Osborne CP, Brakefield PM: Preference for $C_{4}$ shade grasses increases hatchling performance in the butterfly, Bicyclus safitza. Ecol Evol. 2016;6(15):5246-55.

33. Brakefield PM, Reitsma N. Phenotypic Plasticity, Seasonal Climate and the Population Biology of Bicyclus Butterflies (Satyridae) in Malawi. Ecol Entomol. 1991;16(3):291-303.

34. van Bergen E, Brakefield PM, Heuskin S, Zwaan BJ, Nieberding CM. The scent of inbreeding: a male sex pheromone betrays inbred males. Proc $R$ Soc B-Biol Sci. 2013;280(1758):20130102.

35. Beldade P, Peralta CM. Developmental and evolutionary mechanisms shaping butterfly eyespots. Current Opinion in Insect Science. 2017;19:22-9.

36. van Bergen E, Barlow HS, Brattström O, Griffiths $H$, Kodandaramaiah U, Osborne CP, Brakefield PM. The stable isotope ecology of mycalesine butterflies: implications for plant-insect co-evolution. Funct Ecol. 2016; 30(12):1936-46

37. van den Heuvel J, Saastamoinen M, Brakefield PM, Kirkwood TBL, Zwaan BJ, Shanley DP. The Predictive Adaptive Response: Modeling the Life-History Evolution of the Butterfly Bicyclus anynana in Seasonal Environments. Am Nat. 2013;181(2):E28-42.

38. Brakefield PM, Larsen TB. The Evolutionary Significance of Dry and Wet Season Forms in Some Tropical Butterflies. Biol J Linn Soc. 1984;22(1):1-12.

39. Prudic KL, Stoehr AM, Wasik BR, Monteiro A. Eyespots deflect predator attack increasing fitness and promoting the evolution of phenotypic plasticity. Proc $R$ Soc B-Biol Sci. 2015;282(1798):20141531.

40. Lyytinen A, Brakefield PM, Lindstrom L, Mappes J. Does predation maintain eyespot plasticity in Bicyclus anynana? Proc R Soc B-Biol Sci. 2004;271(1536): 279-83.

41. Kooi RE, Brakefield PM. The critical period for wing pattern induction in the polyphenic tropical butterfly Bicyclus anynana (Satyrinae). J Insect Physiol. 1999;45(3):201-12.

42. Prudic KL, Jeon C, Cao H, Monteiro A. Developmental Plasticity in Sexual Roles of Butterfly Species Drives Mutual Sexual Ornamentation. Science. 2011;331(6013):73-5

43. Pijpe J, Brakefield PM, Zwaan BJ. Phenotypic plasticity of starvation resistance in the butterfly Bicyclus anynana. Evol Ecol. 2007;21(5):589-600.

44. Oostra V, de Jong MA, Invergo BM, Kesbeke F, Wende F, Brakefield PM, Zwaan BJ. Translating environmental gradients into discontinuous reaction norms via hormone signalling in a polyphenic butterfly. Proc $\mathrm{R}$ Soc B-Biol Sci. 2011;278(1706):789-97.
45. Zijlstra WG, Steigenga MJ, Koch PB, Zwaan BJ, Brakefield PM. Butterfly selected lines explore the hormonal basis of interactions between life histories and morphology. Am Nat. 2004;163(5):E76-87.

46. Koch PB, Brakefield PM, Kesbeke F. Ecdysteroids control eyespot size and wing color pattern in the polyphenic butterfly Bicyclus anynana (Lepidoptera: Satyridae). J Insect Physiol. 1996;42(3):223-30.

47. Mateus ARA, Marques-Pita M, Oostra V, Lafuente E, Brakefield PM, Zwaan BJ, Beldade P. Adaptive developmental plasticity: Compartmentalized responses to environmental cues and to corresponding internal signals provide phenotypic flexibility. BMC Biol. 2014;12:97.

48. Monteiro A, Tong XL, Bear A, Liew SF, Bhardwaj S, Wasik BR, Dinwiddie A, Bastianelli C, Cheong WF, Wenk MR, et al. Differential Expression of Ecdysone Receptor Leads to Variation in Phenotypic Plasticity across Serial Homologs. Plos Genet. 2015;11(9):e1005529.

49. Oostra V, Mateus ARA, van der Burg KRL, Piessens T, van Eijk M, Brakefield PM, Beldade P, Zwaan BJ. Ecdysteroid Hormones Link the Juvenile Environment to Alternative Adult Life Histories in a Seasonal Insect. Am Nat. 2014;184(3):E79-92.

50. de Jong MA, Kesbeke FMNH, Brakefield PM, Zwaan BJ. Geographic variation in thermal plasticity of life history and wing pattern in Bicyclus anynana. Clim Res. 2010;43(1-2):91-102.

51. Roskam JC, Brakefield PM. A comparison of temperature-induced polyphenism in African Bicyclus butterflies from a seasonal savannahrainforest ecotone. Evolution. 1996;50(6):2360-72.

52. Braby MF. Phenotypic Variation in Adult Mycalesis Hubner (Lepidoptera, Nymphalidae, Satyrinae) from the Australian Wet-Dry Tropics. J Aust Entomol Soc. 1994;33:327-36.

53. Oostra V, Brakefield PM, Hiltemann Y, Zwaan BJ, Brattström O. On the fate of seasonally plastic traits in a rainforest butterfly under relaxed selection. Ecol Evol. 2014;4(13):2654-67.

54. Roskam JC, Brakefield PM. Seasonal polyphenism in Bicyclus (Lepidoptera : Satyridae) butterflies: different climates need different cues. Biol J Linn Soc. 1999;66(3):345-56.

55. Lees DC, Kremen C, Raharitsimba T. Classification, Diversity and Endemism of the Butterflies (Papilionoidea and Hesperioidea): A Revised Species Checklist. In: Goodman SM, Benstead JP, editors. The Natural History of Madagascar. Chicago: University of Chicago Press; 2003. p. 1709.

56. University of East Anglia Climatic Research Unit, Jones PD, Harris I. CRU TS3. 10: Climatic Research Unit (CRU) Time-Series (TS) Version 3.10 of High Resolution Gridded Data of Month-by-month Variation in Climate (Jan. 1901 - Dec. 2009). In. Edited by Centre NBAD. 2013.

57. Gotthard K, Nylin S, Wiklund C. Adaptive Variation in Growth-Rate - LifeHistory Costs and Consequences in the Speckled Wood Butterfly, Pararge aegeria. Oecologia. 1994;99(3-4):281-9.

58. Brakefield PM, Beldade P, Zwaan BJ. The African butterfly Bicyclus anynana: a model for evolutionary genetics and evolutionary developemental biology. In: Behringer R, Johnson A, Krumlauf R, eds. Emerging model organisms: a laboratory manual, vol. 1. Cold Spring Harbor: CSHL Press; 2009. pp. $291-$ 329.

59. Schindelin J, Arganda-Carreras I, Frise E, Kaynig V, Longair M, Pietzsch T, Preibisch S, Rueden C, Saalfeld S, Schmid B, et al. Fiji: an open-source platform for biological-image analysis. Nat Methods. 2012;9(7):676-82.

60. Wijngaarden PJ, Brakefield PM. Lack of response to artificial selection on the slope of reaction norms for seasonal polyphenism in the butterfly Bicyclus anynana. Heredity. 2001;87:410-20.

61. Miller LD. Nomenclature of wing veins and cells. J Res Lepidoptera. 1970; 8(2):37-48.

62. R Development Core Team. R: A language and environment for statistical computing. Vienna: R Foundation for Statistical Computing. URL: http:// www.R-project.org. 2014.

63. Muggeo VMR. Segmented: an R package to fit regression models with broken-line relationships. R news. 2008:8(1):20-5.

64. Davies RB. Hypothesis-Testing When a Nuisance Parameter Is Present Only under the Alternative. Biometrika. 1987;74(1):33-43.

65. Muggeo VMR. Estimating regression models with unknown break-points. Stat Med. 2003;22(19):3055-71.

66. Angilletta MJ, Steury TD, Sears MW. Temperature, growth rate, and body size in ectotherms: Fitting pieces of a life-history puzzle. Integr Comp Biol. 2004;44(6):498-509.

67. Pijpe J, Fischer K, Brakefield PA, Zwaan BJ. Consequences of artificial selection on pre-adult development for adult lifespan under benign 
conditions in the butterfly Bicyclus anynana. Mech Ageing Dev. 2006; 127(10):802-7.

68. Brakefield PM, Kesbeke F, Koch PB. The regulation of phenotypic plasticity of eyespots in the butterfly Bicyclus anynana. Am Nat. 1998;152(6):853-60.

69. Nijhout HF. The development and evolution of butterfly wing patterns: Smithsonian Institution Press. 1991.

70. Beldade P, Brakefield PM. The genetics and evo-devo of butterfly wing patterns. Nat Rev Genet. 2002;3(6):442-52.

71. Brakefield PM, Frankino WA. Polyphenisms in Lepidoptera: Multidisciplinary approaches to studies of evolution and development. In: Phenotypic Plasticity in Insects: Mechanisms and Consequences. Ananthakrishnan TN, Whitman DW eds. Oxford: Oxford University Press.; 2009.

72. Vallin A, Jakobsson S, Lind J, Wiklund C. Prey survival by predator intimidation: an experimental study of peacock butterfly defence against blue tits. Proc R Soc B-Biol Sci. 2005;272(1569):1203-7.

73. Olofsson M, Lovlie H, Tibblin J, Jakobsson S, Wiklund C. Eyespot display in the peacock butterfly triggers antipredator behaviors in naive adult fowl. Behav Ecol. 2013;24(1):305-10.

74. Saastamoinen M, Brommer JE, Brakefield PM, Zwaan BJ. Quantitative genetic analysis of responses to larval food limitation in a polyphenic butterfly indicates environment- and trait-specific effects. Ecol Evol. 2013;3(10):3576-89.

75. Holloway GJ, Brakefield PM, Kofman S, Windig JJ. An Artificial Diet for Butterflies, Including Bicyclus Species, and its Effect on Development Period, Weight and Wing Pattern. J Res Lepidoptera. 1991;30(1-2):121-8.

76. Kooi RE, Brakefield PM, Rossie WEMT. Effects of food plant on phenotypic plasticity in the tropical butterfly Bicyclus anynana. Entomol Exp Appl. 1996; 80(1):149-51.

77. Brakefield PM, Mazzotta V. Matching Field and Laboratory Environments Effects of Neglecting Daily Temperature-Variation on Insect Reaction Norms. J Evolution Biol. 1995;8(5):559-73.

78. Windig JJ, Brakefield PM, Reitsma N, Wilson JGM. Seasonal polyphenism in the wild - survey of wing patterns in 5 species of Bicyclus butterflies in Malawi. Ecol Entomol. 1994:19(3):285-98.

\section{Submit your next manuscript to BioMed Central and we will help you at every step:}

- We accept pre-submission inquiries

- Our selector tool helps you to find the most relevant journal

- We provide round the clock customer support

- Convenient online submission

- Thorough peer review

- Inclusion in PubMed and all major indexing services

- Maximum visibility for your research

Submit your manuscript at www.biomedcentral.com/submit
Biomed Central 